\title{
Formation of Andrographolide- $\beta$-cyclodextrin Inclusion to Increase Solubility and Dissolution Rate
}

\author{
Bayu F. Prasetyo*, Ietje Wientarsih, Dondhin Sajuthi, Vetnizah Juniantito
}

Department of Clinic, Reproduction, and Pathology, Faculty of Veterinary Medicine, Bogor Agricultural University, Bogor, Indonesia

Submitted 21 December 2017 ; Revised 09 February 2018 ; Accepted 14 February 2018 ; Published 27 June 2018 *Corresponding author: bayupr@apps.ipb.ac.id

\begin{abstract}
Andrographolide (AG) is a pure isolate of the chemical synthesis of sambiloto (Andrographis paniculata Nees.) which has various pharmacological properties such as anti-inflammatory and antimicrobial. In order to improve the ability of AG to penetrate the membrane in transdermal use, an inclusion complex was formed using $\beta$-cyclodextrin (BCD) by modifying the physical chemistry properties of AG, particularly the solubility in its base, partition, and distribution on the skin, as well as by changing the permeability of the stratum corneum. The inclusion complexes of AG with BCD were prepared by the solvent evaporation method in the mole ratios of 1:1, 1:2, and 2:1. The solid of the yield of $A G$ inclusion complex in BCD has been tested with a solubility test until it reached equilibrium at $37 \pm 5^{\circ} \mathrm{C}$ for 24 hours and In vitro dissolution rate test using the II USP method (paddle type), then compared to a single AG compound, and a physical mixture of AG-BCD. Based on the solubility and dissolution rate tests, it showed that the formation of AG-BCD inclusion complex was obtained at the mole ratio of 1:2. Moreover, the AG solubility increased 38 times and the dissolution rate in the $60^{\text {th }}$ minute increased twice in the inclusion complex with BCD.
\end{abstract}

Keywords: $\beta$-cyclodextrin, andrographolide, dissolution rate, inclusion complex, solubility.

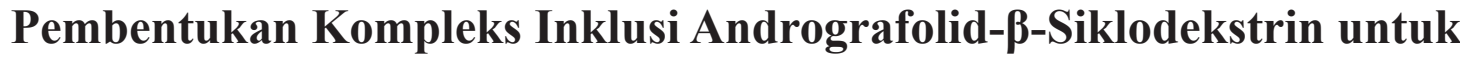 Meningkatkan Kelarutan dan Laju Disolusi}

\begin{abstract}
Abstrak
Andrografolid (AG) merupakan isolat murni hasil sintesis kimiawi herba sambiloto (Andrographis paniculata Nees.) yang memiliki beragam khasiat farmakologi antiinflamasi dan antibakteri. Untuk meningkatkan kemampuan AG menembus membran jika digunakan secara transdermal, dilakukan pembentukan kompleks inklusi menggunakan $\beta$-siklodektrin (BCD) dengan memodifikasi sifat fisiko kimia AG terutama kelarutan dalam basis, partisi, dan distribusinya pada kulit, serta merubah permeabilitas stratum corneum. Kompleks inklusi AG dengan BCD dibuat dengan metode penguapan pelarut dengan perbandingan mol 1:1, 1:2, dan 2:1. Padatan hasil kompleks inklusi AG dalam BCD dilakukan uji kelarutan hingga mencapai kesetimbangan pada suhu $37 \pm 5^{\circ} \mathrm{C}$ selama 24 jam serta uji laju disolusi in vitro menggunakan metode II USP (alat tipe dayung, kemudian dibandingkan terhadap senyawa tunggal AG, dan campuran fisik AG-BCD. Berdasarkan hasil uji kelarutan dan laju disolusi menunjukkan terbentuknya kompleks inklusi AG-BCD adalah pada perbandingan mol 1:2. Data kelarutan AG meningkat 38 kali lipat dan laju disolusi meningkat dari 2 kali lipat dalam kompleks inklusi dengan $\mathrm{BCD}$.
\end{abstract}

Kata Kunci: $\beta$-siklodektrin, andrografolid, kelarutan, kompleks inklusi, laju disolusi. 


\section{Pendahuluan}

Kelarutan memiliki peran penting dalam menentukan bentuk sediaan dan untuk menentukan konsentrasi yang dicapai pada sirkulasi sistemik untuk menghasilkan respon farmakologi ${ }^{1}$. Senyawa yang relatif tidak dapat dilarutkan mungkin memperlihatkan absorbsi yang tidak sempurna sehingga respon terapeutiknya menurun. Daya larut dalam air dapat ditingkatkan salah satunya dengan teknik kompleksasi².

Kompleks inklusi merupakan kompleks yang terbentuk dari dua molekul melalui interaksi non-kovalen. Proses pembentukan kompleks inklusi terutama dipengaruhi oleh sifat hidrofobik senyawa obat (guest) yang berinteraksi dengan bagian dalam rongga siklodekstrin. Selain itu terjadinya interaksi juga dipengaruhi oleh bentuk dan ukuran senyawa obat. Sifat fisikokimia senyawa obat dapat berubah karena terbentuk kompleks inklusi yang dapat meningkatkan kelarutan, laju disolusi, bioavailabilitas, dan stabilitas obat $^{3}$. Dibandingkan dengan bentuk molekul bebas, molekul obat yang terkompleks siklodekstrin memiliki sifat fisika kimia yang baru, salah satunya yaitu kelarutan di dalam air meningkat. Diantara golongan siklodekstrin, beta-siklodekstrin (BCD) paling banyak digunakan pada pengembangan formula dan sistem penghantaran obat ${ }^{4}$. Penelitian sebelumnya menunjukkan pembentukan kompleks inklusi meloksikambeta siklodekstrin menghasilkan kecepatan disolusi yang lebih baik daripada meloksikam tanpa kompleksasi. Pembentukan kompleks nitrepidin-hidroksipropil beta siklodekstrin dengan metode solvent evaporation juga diketahui dapat meningkatkan kecepatan disolusi dibandingkan tanpa kompleksasi ${ }^{5}$. Berdasarkan beberapa penelitian sebelumnya diduga bahwa senyawa siklodekstrin dapat meningkatkan penetrasi perkutan dengan cara memodifikasi sifat fisiko kimia obat terutama kelarutan dalam basis, partisi dan distribusi obat pada kulit serta merubah permeabilitas stratum corneum.

Andrografolid (AG) merupakan isolat murni hasil sintesis kimiawi herba sambiloto (Andrographis paniculata Nees.).
AG berupa kristal berbentuk jarum tak berwarna, mempunyai rasa yang sangat pahit dengan rumus molekul $\mathrm{C}_{20} \mathrm{H}_{30} \mathrm{O}_{5}$, bobot molekul 350,5, titik lebur 228$230^{\circ} \mathrm{C}$, dan memiliki spektrum ultraviolet dalam metanol pada panjang gelombang maksimum $230 \mathrm{~nm}$ dengan beragam khasiat farmakologi diantaranya antiinflamasi, antidiabetes, antihiperlipidemia, antikanker, immunomodulator, kardioprotektor, hepatoprotektor, antimikrobial, antiviral, dan antiparasitik ${ }^{7,8}$. AG sukar larut dalam air. Kelarutannya dalam air pada suhu $25^{\circ} \mathrm{C}$ sebesar $60 \mathrm{mg} / \mathrm{L}^{9}$. Hal ini menyebabkan rendahnya kemampuan melarut, menembus membran, dan distribusi obat jika digunakan pada kulit atau transdermal. Penelitian sebelumnya menunjukkan bahwa pemberian obat yang mengandung andrografolid secara transdermal lebih baik dilakukan daripada secara oral ${ }^{10}$. Penelitian sebelumnya ${ }^{11}$ juga menunjukkan bahwa andrografolid yang digunakan secara topikal dapat menyembuhkan luka lebih cepat.Oleh karena itu perlu ditingkatkan kelarutan AG dalam air agar efeknya optimal. Modifikasi sifat kelarutan AG untuk meningkatkan kemampuan menembus membran dilakukan melalui pembentukan kompleks inklusi dengan BCD.

Keberhasilan pembentukan kompleks inklusi AG dalam BCD dibandingkan kelarutan AG dicapai pada kondisi kesetimbangan (jenuh), serta berpengaruh terhadap persentase AG yang terlarut dalam satuan waktu melalui pengujian laju disolusi. Parameter meningkatnya persentase kelarutan dan laju disolusi dapat dijadikan acuan bagi keberhasilan siklodektrin dalam membentuk komplek inlklusi dengan senyawa androgafolid.

\section{Metode}

2.1. Alat

Spektrofotometer UV (Shimadzu UVmini-1240), dissolution tester (merk LID6), magnetic stirrer-hot plate (merk Thermo scientific), pengaduk orbital (GFL 1092), timbangan analitik (Mettler Toledo AG204), vortex mixer (Thermo Scientific) 


\subsection{Bahan}

Androgafolid (Plamed, China), Betasiklodekstrin (Eks PT. Sanbe Farma), dinatrium hidrogen fosfat $\left(\mathrm{Na}_{2} \mathrm{HPO}_{4}\right)$ (merk Sigma Aldrich), kalium dihidrogen fosfat $\left(\mathrm{KH}_{2} \mathrm{PO}_{4}\right)$ (merk Sigma Aldrich), metanol pro analisis, dan aquadest.

\subsection{Prosedur Rinci}

Senyawa kompleks inklusi AG-BCD dibuat dengan metode penguapan pelarut (solvent evaporation) yang dilanjutkan dengan uji kelarutan jenuh dan uji laju disolusi sehingga terpilih satu perbandingan yang membentuk senyawa kompleks inklusi antara $\mathrm{AG}$ dengan $\mathrm{BCD}$.

\subsubsection{Pembentukan kompleks inklusi AG-} BCD dengan metode penguapan pelarut (solvent evaporation)

Masing-masing bahan AG dan BCD ditimbang berdasarkan perbandingan mol 1:1, 1:2 dan 2:1. Kemudian AG dilarutkan dalam metanol sedangkan BCD dilarutkan dalam aquadest. Keduanya dicampurkan dengan pengadukan konstan berkecepatan 500 rpm selama 24 jam. Campuran ini didiamkan pada suhu kamar untuk menguapkan pelarut hingga diperoleh endapan. Setelah mengering, endapan senyawa kompleks inklusi yang terbentuk diayak dengan ayakan mesh 20, kemudian disimpan di dalam desikator.

\subsubsection{Uji kelarutan jenuh}

Serbuk kompleks inklusi AG-BCD yang sebelumnya dihasilkan dari metode penguapan pelarut masing-masing pada perbandingan 1:1, 1:2 dan 2:1 ditimbang berlebih setara dengan $50 \mathrm{mg}$ serbuk AG murni. Kemudian dimasukkan kedalam vial kaca berisi larutan dapar fosfat 7,4 sebanyak $10 \mathrm{~mL}$. Sampel diaduk dengan menggunakan shaker waterbath pada suhu konstan $37^{\circ} \mathrm{C} \pm 0,5^{\circ} \mathrm{C}$, kecepatan 50 putaran/menit. Pengadukan dilakukan hingga tercapai kesetimbangan. Sampel larutan disaring dengan kertas saring Whatman dan diencerkan secara tepat. Kemudian kadar AG dalam bentuk murni maupun dalam bentuk kompleks inklusi ditetapkan dengan spektrofotometer UV pada panjang gelombang serapan maksimum 230 nm.

\subsubsection{Uji laju disolusi}

Sejumlah $5 \mathrm{mg}$ serbuk AG murni, ditimbang dengan neraca analitis. campuran fisik AG-BCD yang dibuat dengan cara mencampurkan kedua bahan tersebut dan kompleks inklusi AG-BCD ditimbang setara dengan AG murni $5 \mathrm{mg}$, ditetapkan dengan metode II USP (alat tipe dayung), kecepatan pengadukan 50 putaran per menit, medium disolusi dapar fosfat $\mathrm{pH} 7.4$ sebanyak $900 \mathrm{~mL}$, suhu $37 \pm 5^{\circ} \mathrm{C}$. Larutan sampel diambil pada interval waktu $5,10,15,20,30,40,50$ dan 60 menit sebanyak $10 \mathrm{~mL}$, kemudian segera diganti dengan medium disolusi sebanyak 10 $\mathrm{mL}$ pada suhu yang sama. Larutan sampel disaring dengan menggunakan kertas saring Whatman no 01 kemudian diukur serapannya menggunakan spektrofotometer UV yang sudah divalidasi pada panjang gelombang serapan maksimum $230 \mathrm{~nm}$.

\section{Hasil}

Berdasarkan data kelarutan, AG dan BCD berturut-turut mudah larut dalam metanol dan aquadest. Kompleks inklusi AG-BCD dibuat berdasarkan perbandingan mol 1:1, 1:2 dan 2:1, dengan bobot yang diperlukan sesuai pada Tabel 1 .

Uji kelarutan jenuh adalah uji kelarutan yang dilakukan hingga kadar sampel yang terlarut sudah mencapai kondisi jenuh atau kesetimbangan. Hasil Uji kelarutan jenuh serbuk kompleks inklusi AG-BCD pada perbandingan mol 1:1, 1:2 dan 2:1 dibandingkan terhadap serbuk AG murni dan campuran fisik keduanya. Semua sampel mencapai kondisi jenuh pada waktu 24 jam dengan penimbangan berlebih pada AG. Penimbangan kesetaraan kompleks inklusi AG-BCD terhadap $50 \mathrm{mg}$ AG serta data hasil kelarutan dapat dilihat pada Tabel 2.

Uji laju disolusi bertujuan untuk mengetahui berapa banyak serbuk kompleks inklusi AG-BCD yang terlarut pada interval waktu tertentu dalam medium cair dengan volume yang diketahui dan suhu yang relatif konstan. Data hasil uji laju disolusi 
Tabel 1. Bobot yang Diperlukan Sesuai dengan Perbandingan Mol

\begin{tabular}{|c|c|c|c|}
\hline \multirow{2}{*}{ Bahan } & \multicolumn{3}{|c|}{$\begin{array}{c}\text { Bobot yang ditimbang } \\
\text { berdasarkan perbandingan mol } \\
(\mathrm{g})\end{array}$} \\
\hline & $1: 1$ & $1: 2$ & $2: 1$ \\
\hline Andrografolid & 0,701 & 0,701 & 1,402 \\
\hline Betasiklodekstrin & 2,270 & 4,540 & 2,270 \\
\hline
\end{tabular}

serbuk kompleks inklusi AG-BCD pada perbandingan mol 1:1, 1:2 dan 2:1 yang dibandingkan terhadap serbuk AG murni dan campuran fisik keduanya dapat dilihat pada Tabel 3.

\section{Pembahasan}

Perbandingan mol yang terbentuk pada kompleks inklusi ditandai dengan terperangkapnya molekul guest. AG secara keseluruhan maupun sebagian terperangkap dalam rongga host, dalam hal ini host adalah BCD yang ditunjukkan melalui uji karakterisasi pada penelitian sebelumnya ${ }^{12}$. Pemilihan perbandingan mol 1:1 dilakukan untuk melihat kemampuan membentuk kompleks inklusi antara 1 mol AG dengan 1 mol BCD terhadap peningkatan kelarutan AG. Perbandingan mol 1:2 dibuat untuk melihat pengaruh peningkatan jumlah mol BCD terhadap kelarutan AG dalam kompleks inklusi AG-BCD. Perbandingan mol 2:1 dibuat untuk melihat pengaruh penurunan jumlah mol BCD terhadap kelarutan AG
Tabel 2. Bobot yang Diperlukan dari Hasil Kelarutan

\begin{tabular}{lcc}
\hline \multicolumn{1}{c}{ Bahan } & $\begin{array}{c}\text { Bobot yang } \\
\text { Ditimbang } \\
(\mathrm{mg})\end{array}$ & $\begin{array}{c}\text { Kelarutan } \\
(\mathrm{mg} / \mathrm{mL})\end{array}$ \\
\hline Andrografolid (AG) & 50 & 0,00937 \\
Campuran Fisik (CF) & 211,91 & 0,1111 \\
KI AG-BCD (1:1) & 211,91 & 0,1578 \\
KI AG-BCD (1:2) & 373,82 & 0,3605 \\
KI AG-BCD (2:1) & 261,91 & 0,0619 \\
\hline
\end{tabular}

Keterangan: $\mathrm{MR}$ AG $=350,5$

$\mathrm{MR} \mathrm{BCD}=1135$

dalam kompleks inklusi AG-BCD.

Mekanisme pembentuka kompleks inklusi diawali dengan terjadinya pendekatan molekul siklodekstrin terhadap molekul guest, kemudian terjadi kerusakan struktur air di dalam cincin siklodekstrin dan pemindahan beberapa molekul air dari cincin siklodekstrin. Selanjutnya terjadi kerusakan struktur air di sekitar bagian molekul guest dan pemindahan molekul air guest ke dalam larutan sehingga molekul guest dapat masuk ke dalam molekul siklodekstrin ${ }^{5}$.Interaksi molekul guest pada bagian dalam siklodekstrin terjadi karena pembentukan ikatan hidrogen antara guest dan siklodekstrin. Monomer siklodekstrin membentuk ikatan hidrogen intramolekuler kemudian membentuk ikatan hidrogen intermolekular dengan molekul air dalam larutan cair termasuk dengan molekul guest yang masuk ke dalam rongganya ${ }^{13}$.

Hasil uji kelarutan jenuh serbuk kompleks inklusi AG-BCD menunjukkan peningkatan kelarutan $\mathrm{AG}$ jika dibandingkan serbuk AG murni dan campuran fisik

Tabel 3. Hasil Uji Disolusi

\begin{tabular}{cccccc}
\hline \multirow{2}{*}{$\begin{array}{c}\text { Waktu } \\
\text { (menit ke-) }\end{array}$} & AG & CF & KI 1:1 & KI 1:2 & KI 2:1 \\
\cline { 2 - 6 } & 12,88 & 59,22 & 59,23 & 70,07 & 49,51 \\
5 & 21,23 & 67,98 & 72,23 & 74,07 & 51,11 \\
10 & 23,00 & 72,24 & 73,08 & 75,71 & 57,87 \\
15 & 24,79 & 74,25 & 76,99 & 77,40 & 61,25 \\
20 & 27,74 & 75,12 & 79,43 & 82,15 & 66,97 \\
30 & 32,74 & 77,55 & 80,36 & 84,27 & 67,77 \\
40 & 38,10 & 79,61 & 82,84 & 87,94 & 72,03 \\
50 & 44,67 & 88,73 & 89,49 & 95,50 & 79,79 \\
60 & & & &
\end{tabular}




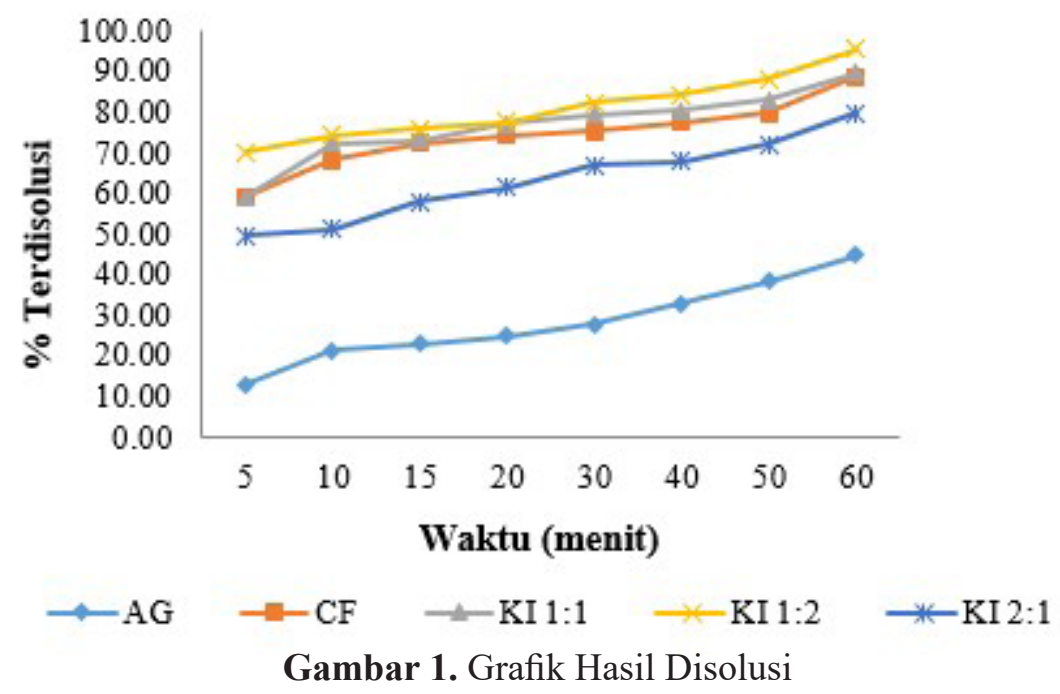

keduanya. Hal ini sesuai dengan hasil penelitian sebelumnya yang menyebutkan pembentukan kompleks inklusi menggunakan metode solvent evaporation menghasilkan peningkatan kelarutan pada norfloxacin lebih tinggi daripada metode campuran fisik ${ }^{14}$. Peningkatan kelarutan terlihat pada kompleks inklusi AG-BCD perbandingan mol 1:2 yaitu sebanyak 38 kali dari kelarutan AG murni. Pada kompleks inklusi ini, jumlah mol BCD lebih banyak dibandingkan jumlah mol AG. Hal ini membuktikan bahwa semakin banyak jumlah mol BCD dalam kompleks inklusi akan semakin meningkatkan kelarutan AG.

AG murni pada menit ke-60 terdisolusi sebanyak 44,67\%, menunjukkan profil laju disolusi paling rendah jika dibandingkan dengan campuran fisika AG-BCD dan kompleks inklusi AG-BCD. Terjadinya peningkatan laju disolusi pada campuran fisik AG-BCD dan kompleks inklusi AG$\mathrm{BCD}$ dimungkinkan karena $\mathrm{AG}$ terkompleks dalam suatu matriks BCD yang bagian luarnya hidrofilik dan bagian dalam rongga bersifat hidrofobik. Zat yang memiliki masalah kelarutan dalam air akan membentuk kompleks inklusi dalam rongga $\mathrm{BCD}$ sehingga meningkatkan kelarutan dan laju disolusi dibandingkan dengan zat tunggal ${ }^{15}$. Peningkatan laju disolusi yang signifikan terlihat pada kompleks inklusi AG-BCD perbandingan mol 1:2, yaitu pada menit ke60 terdisolusi sebanyak 95,50\% meningkat 2 kali lipat.

\section{Kesimpulan}

Profil uji kelarutan jenuh dan laju disolusi yang menunjukkan terbentuknya kompleks inklusi AG-BCD adalah pada perbandingan mol 1:2, yang ditandai dengan meningkatnya kelarutan AG 38 kali lipatdan laju disolusi pada menit ke-60 meningkat 2 kali lipat.

\section{Ucapan Terima Kasih}

Ucapan terimakasih diberikan kepada Program Pasca Sarjana Ilmu Biomedis Hewan Institut Pertanian Bogor dan Departemen Klinik Reproduksi dan Patologi Fakultas Kedokteran Hewan Institut Pertanian Bogor.

\section{Daftar Pustaka}

1. Pramudhita WYPA, Hendriani R. Review: teknik peningkatan kelarutan obat. Farmaka. 2017;14(2):288-297.

2. Sari YN, Syofyan, Matagi Y. Karakterisasi kompleks inklusi ketokonazol-ßsiklodekstrin menggunakan metode cogrinding berdasarkan variasi mol. Jurnal Farmasi Higea. 2015;7(2):111-119.

3. Bilensoy E, Duchene D. Cyclodextrins in Pharmaceutics, Cosmetics, and Biomedicine: Current and Future Industrial Application. New Jersey: John Wiley and Sons Ltd; 2011

4. Sambasevam KP, Mohamad S, Sarih, NM, Ismail NA. Synthesis and characterization of the inclusion complex 
of beta-cyclodextrin and azomethine. Int J Mol Sci. 2013;14(2):3671-82.

5. Bestari AN. Penggunaan siklodekstrin dalam bidang farmasi. Majalah Farmaseutik. 2014:10(1):197-201.

6. Agustin R, Goeswin A, Sasanti T. Studi pengaruh kompleks siklodekstrin terhadap penetrasi perkutan piroksikam. Jurnal Farmasi Indonesia. 2007:3(3):111118.

7. Chen HW, Lin AH, Chu HC, Li CC, Tsai CW, Chao CY, Wang CJ, Lii CK, Liu KL. Inhibition of TNF- $\alpha$-inducedinflammation by andrographolide via down-regulation of the PI3K/Akt signaling pathway. J .Nat Product. 2011:74(11):2408-2413.

8. Jayakumar T, Hsieh CY, Lee JJ, Sheu JR. Experimental and clinical pharmacology of Andrographis paniculata and its major bioactive phytoconstituent andrographolide. EvidBased Complement Alternat Med. 2013:2013:ID846740

9. Rosindah I, Sumaryono W, Surini S. Peningkatan kelarutan androgafolid dalam fraksi etil asetat herba sambiloto (Andrographis paniculata Nees) melalui mikroenkapsulasi dengan metode semprot kering. Jurnal Ilmu Kefarmasian Indonesia. 2014:April:80-92.

10. Ding DY. Studies on the transports and pharmacokinetics of andrographolide in rats (disertasi) [diunduh 8 Februari 2018]. Tersedia di: www.globethesis. $\mathrm{com} / ? \mathrm{t}=1114360272996745$

11. Al-Bayat FH, Abdulla Ma, Abu Hassan MI, Ali MH. Effect of andrographis paniculata leaf extract on wound healing in rats. Nat Prod Res. 2012:25(5):423-9.

12. Prasetyo BF, Wientarsih I, Sajuthi D, Juniantito V. Characterization of andrographolide in inclusion complex using beta siklodextrin. IJPSR. 2018:9(3):1000-05

13. Kohler JEH and Grczelschak-Mick N. The $\beta$-cyclodextrin/benzene complex and its hydrogen bonds- a theoretical study using molecular dynamics, quantum mechanics and COSMO-RS. 2013:9:118134.

14. Loh GOK, Tan YTF, Peh KH. Enhancement of norfloxacin solubility via inclusion complexation with $\beta$-siklodekstrin and its derivative hydroxypropyl- $\beta$-siklodekstrin. 2016. Asian Journal of Pharmacetical Science . 2016:11(2016):536-546

15. Agustin R, Lestari FI, Halim A. Pembentukan dan karakterisasi kompleks inklusi fenilbutazon dan $\beta$-siklodekstrin dengan metoda co-grinding. Kartika Jurnal Ilmiah Farmasi. 2015:3(1):14-19. 